\title{
Distribution of microglial clusters in the brain after head injury
}

\author{
J. M. CLARK ${ }^{1}$ \\ From the Burden Neuropathological Laboratory, Frenchay Hospital, Bristol
}

SYNOPSIS The brains of 12 cases of head injury have been submitted to gross pathological study and microscopic examination by the Weil-Davenport method, with special reference to the corpus callosum, internal capsules, and brain-stem in each case. Microglial clusters were observed in 11 out of 12 cases, the most common sites for these being the corpus callosum ipsilateral to the external applied force and the internal capsule and brain-stem contralateral to this applied force. This pattern of distribution of lesions remained constant in all cases. The nature, aetiology, and distribution of these lesions is discussed and it is concluded that such lesions arise from the formation of definite patterns of shearing forces which snap axons. These forces arise from the rotational movements set up within the skull resulting from the relative delay of movement of the brain with respect to the skull and dura mater.

When the head undergoes sudden acceleration, injuries to the brain may take the form of gross lacerations, frequently at the site of a fracture, contusions, haemorrhages, and infarcts, or of widely scattered small areas of disrupted nerve fibres. These latter lesions were in the past frequently attributed to systemic disturbances resulting from bodily injury-for example, anoxia, vascular disturbance, or fat embolism. A very full discussion of these mechanisms will be found in the papers by Strich $(1956 a, b, 1961)$ who, while admitting that such secondary changes do occur, stressed the part played by purely mechanical forces operating at the moment of impact.

Evidence for direct physical trauma being the cause of these widespread lesions has been slow to accumulate. Nevertheless, evidence of torn axon fibres was found in the form of retraction bulbs near small areas of haemorrhage by Rand and Courville (1934), and Strich (1956a, b, 1961) has confirmed this. The view that blood vessels are stretched or ruptured, which recognizes the transmission of the force through the brain substance, was propounded by many workers (Bright, 1831; Schmaus, 1899; Jakob, 1913; Denny-Brown and Russell, 1941). Similarly, the

1 Present address: Royal United Hospital, Combe Park, Bath, Somerset BA1 3NG. view that axons might be ruptured by direct force is an old one (Gama, 1835; Jakob, 1913). Gama believed that the axons were damaged by 'vibration', but the work of Holbourn (1943, 1945) and Pudenz and Shelden (1946) suggests that the gliding and swirling movements of the cerebrum within the cranial cavity may set up shearing forces within the brain substance. Certainly the theory was based on purely physical measurements using a very approximate model for the brain, but Strich's work has shown histological features compatible with such a theory. Indeed, Holbourn's explanation for the resolution of these shearing forces (Holbourn, 1956, personal communication in the thesis by Strich) would fit very well with the distribution of the lesions described by Strich.

As previously noted, little confirmatory evidence exists for this view, as few workers have submitted the brains of head injury victims to detailed microscopic investigation. Strich attributes this partly to the difficulty of visualizing by routine histological methods what are often slight and widely scattered lesions.

More recently, Oppenheimer (1968) has studied the distribution of these microscopic lesions by identifying areas of microglial reaction by the method of Weil and Davenport (1933). 
This provides a rapid method of scanning for these small areas of brain damage. Such lesions are claimed to correspond with the glial stars noted by Strich.

The microglial reaction is essentially a nonspecific phagocytic response which may occur with various types of neurological damage. In the type of case studied by Oppenheimer, it is a response to axon disruption or petechial haemorrhage within the brain substance (see Luse, 1968).

This paper describes further the distribution of the microglial clusters in cases of head injury resulting from localized external trauma to the skull.

\section{METHODS}

Of 57 cases of head injury, all but 12 were excluded because the severity of the gross lesions precluded taking all the desired blocks, or because the survival time was considered insufficient. A minimum survival time of 18 hours was used to select cases, as the microglial clusters which were to be studied are not normally present before this time (Oppenheimer, 1968).

The 12 remaining cases had survival times ranging from 23 hours to 277 days, and the brains had been stored in $10 \%$ formalin solution for as long as $2 \frac{1}{2}$ years when examined:

Gross injuries were noted on the sliced brains, followed by the main investigation by the WeilDavenport staining technique for microglial reaction which was carried out on $25 \mu \mathrm{m}$ frozen sections. The method was, however, modified by adding the fol- lowing procedures to the basic technique. (1) After silver impregnation, reduction in formalin, and washing three times in distilled water as described by Weil and Davenport (1933), the sections were toned by immersion in $0.25 \%$ gold chloride solution for $T$ eight minutes. (2) Sections were then washed once in distilled water. (3) Sections were transferred to $5 \%$ sodium thiosulphate solution for five minutes to fix the gold and silver.

By this method microglia are stained densely black against a blue-grey background. As noted by Oppenheimer and Weil and Davenport, artefacts in the form of granular deposits, or generalized black stippling of the background, especially of grey matter and the margins of sections, were noted in cases stored for more than six months.

The following sites were sampled in each case: (1) at least one level of the corpus callosum; (2) the left and right internal capsules; (3) the middle cerebellar peduncles. These sites were particularly chosen since they represent large fibre bundles whose longitudinal axis can reasonably be assessed. It may also be noted that these fibre bundles represent three main axes is roughly at right angles, although in fact the parts of the internal capsule investigated occupy two of these axes.

In two cases the following further investigations were carried out: (a) on frozen sections-(1) Gros $\rightarrow$ Bielschowsky stain, (2) Marchi stain for myelio degeneration, (3) Herzheimer stain for neutral fat $\overrightarrow{0}$ (b) on paraffin sections-(1) haematoxylin ang eosin, (2) Holmes silver impregnation for axons.

The distribution of lesions was noted initially in each case and the results from each case were superimposed in Figs 7 and 8 to emphasize the lateralization of lesions.

TABLE 1

CliniCAL AND PATHOlOGICAL FEATURES*

\begin{tabular}{|c|c|c|c|c|c|c|}
\hline Case & $\begin{array}{c}\text { Survival } \\
\text { (days) }\end{array}$ & $\begin{array}{c}\text { Highest } \\
\text { attained } \\
\text { consciousness }\end{array}$ & Area of impact & Fractures & $\begin{array}{c}\text { Contusions/ } \\
\text { lacerations } \\
\text { (hemisphere) }\end{array}$ & $\begin{array}{l}\text { Intracranial } \\
\text { haemorrhage }\end{array}$ \\
\hline 1 & 13 & +++ & $\mathbf{R}$ parietal & 0 & $\mathbf{L}+\mathbf{R}$ & 0 \\
\hline 2 & 277 & + & $\mathbf{R}$ parietotemporal & $\mathbf{R}$ parietotemporal & $\mathbf{L}+\mathbf{R}$ & L subdural \\
\hline 3 & 26 & ++++ & R-sided & Ant. fossa & $\mathbf{L}+\mathbf{R}$ & 0 \\
\hline 4 & 30 & 0 & L-sided & $\mathbf{0}$ & $\mathbf{L}>\mathbf{R}$ & 0 \\
\hline 5 & 17 & +++ & None apparent & 0 & 0 & 0 \\
\hline 6 & 62 & ++ & L temporoparietal & $\mathbf{L}+\mathbf{R}$ temporoparietal & $\mathbf{L}+\mathbf{R}$ & L subdural \\
\hline 7 & 25 & ++ & $\mathbf{L}$ parietal & $L$ parietal & $\mathbf{L}$ & $\mathbf{R}$ subdural \\
\hline 8 & 107 & + & $L$ parietal & $L$ parietal & $\mathbf{R}$ & L extradural \\
\hline 9 & 49 & + & L sided & 0 & $\mathbf{L}+\mathbf{R}$ & L extradural \\
\hline 10 & 7 & ++ & None apparent & 0 & $\mathbf{R}>\mathbf{L}$ & 0 \\
\hline 11 & $23 \mathrm{hr}$ & + & Occipital & Occipital & $\mathbf{L}>\mathbf{R}$ & 0 \\
\hline 12 & 7 & + & $\mathbf{R}$ parietotemporal & $\mathbf{R}$ temporal & $\mathbf{L}+\mathbf{R}$ & Extradural \\
\hline
\end{tabular}

* All cases showed a mild degree of sub-arachnoid bloodstaining. 0 Indicates absence of a feature.

+0 Unresponsive to all stimuli. + Responding to painful stimuli only. ++ Responding to commands. +++ Conscious but drowsy. +++++ Fully conscious. 


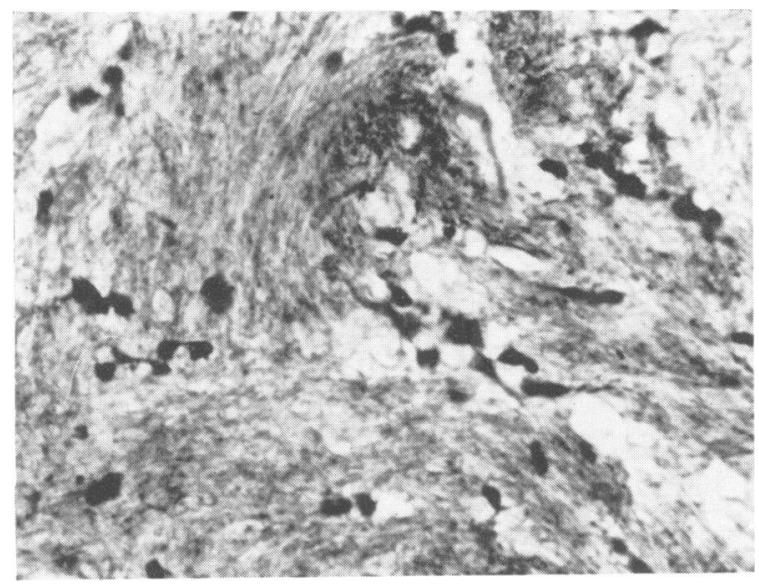

FIG. 1. Case 11. Photomicrograph of section from the superior cerebellar peduncle; 23 hours' survival. A group of microglial cells with few processes is seen and the cells have not aggregated to form a definite cluster. Weil-Davenport stain, $\times 256$.

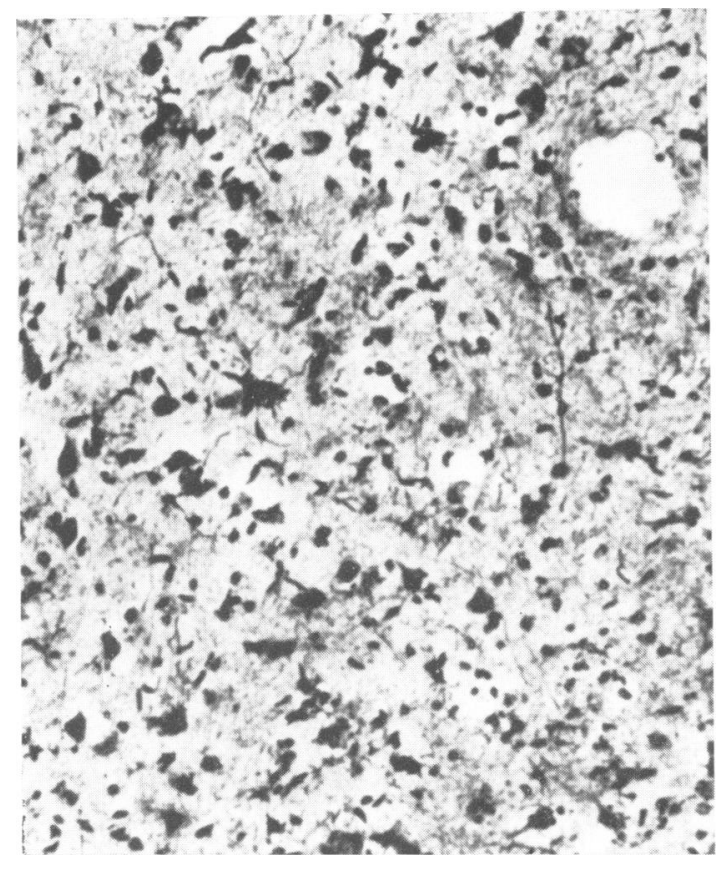

FIG. 2. Case 10. Photomicrograph of section from the right middle cerebellar peduncle; seven days' survival. An extensive area of microglial proliferation is seen, the cells still having poorly developed processes. WeilDavenport stain, $\times 96$.

\section{RESULTS}

Clinical and gross pathological features of the cases are summarized in Table 1 . In every case except case 5 there was some period of loss of consciousness, and only three of the 12 cases showed any return to consciousness before death. In the seven cases where skull fracture had occurred, gross lacerations were most common ipsilateral to the fracture with contralateral contusions-fitting in well with the concept of coup and contrecoup lesions. Scattered petechial haemorrhages seen in some cases, and often associated with minute areas of softening, were considered to be due to direct acceleration injury since there was no evidence of compression injury.

Microglial clusters were found in 11 of the 12 cases, the exception again being case 5 , in which the history of loss of consciousness before admission was doubtful and evidence of severe trauma was lacking (Table 1). Typical examples of microglial clusters are shown in Figs 1 to 4 and show the variations which occur with time. Thus, in case 11 (Fig. 1) where survival was for only 23 hours, microglial cells are few with little definite cluster formation and the cell processes are poorly developed. This contrasts with case 3 (Figs 3 and 4) where the cells have a profuse development of processes.

In the present series, the rate of development of microglial cells appeared to be slower than that described by Oppenheimer (1968), although the degree of development of the cells showed no 


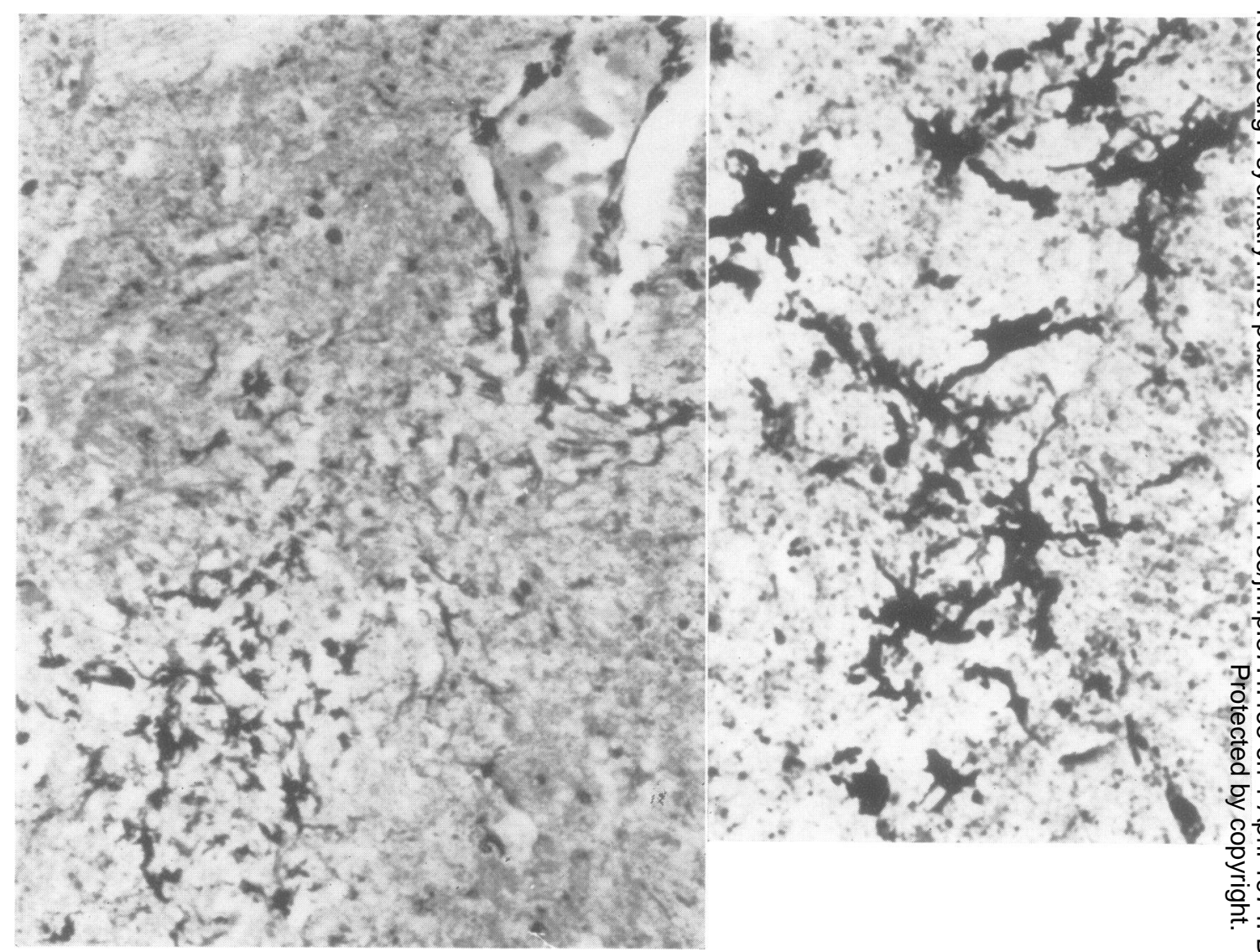

FIG. 3 (left) Case 3. Photomicrograph of section from the right middle cerebellar peduncle; 26 days' survival. $A$ well-defined microglial cluster lies close to a small blood vessel, seen in the top right-hand corner. WeilDavenport stain, $\times 96$.

FIG. 4 (right) Case 3. Photomicrograph of the cluster in Fig. 3, showing the high degree of development of the cell processes at this stage. Weil-Davenport stain, $\times 256$.

constant relationship to the length of survival. Cases of long survival frequently showed transition of microglial cells into fat-laden phagocytes.

The distribution of the microglial clusters is set out in Table 2 and Figs 5 to 8 . Microglial clusters were most commonly found in the white matter, being most frequently found in those parts of the brain occupied by the long fibre bundles. Lesions of the corpus callosum were the most universal finding, all 11 cases with microglial lesions having them in this site. Only one of these 11 cases lacked such lesions in the internal capsule. These latter lesions were usually predominantly on the contralateral side to the lesions of the corpus callosum, which were most frequent on the same side as that of impact. This feature can be seen more clearly in Figs 7 and 8 where the results of all cases with unilateral external trauma are superimposed. In the brainstem, lesions were most frequent in the long tracts of the midbrain and upper pons, usually predominantly ipsilateral to the lesions of the internal capsule (Figs 5, 7, and 8). In only six cases were there lesions of the medulla.

Lesions of the cerebral white matter, other than in the above-mentioned sites, were sought in only two cases (4 and 8), but lesions were found in each case (Fig. 6) predominantly ipsi- 


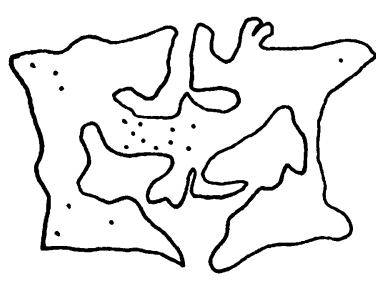

(a)

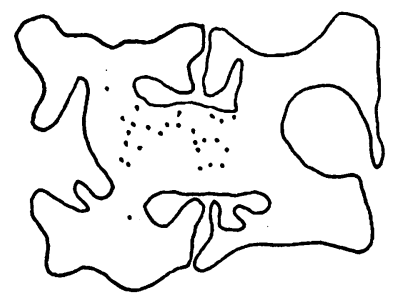

(e)

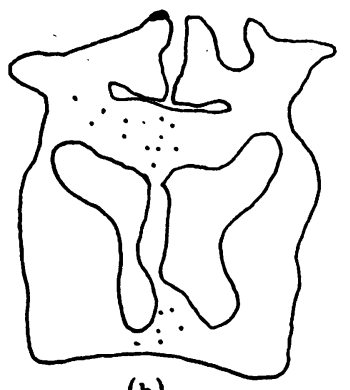

(b)

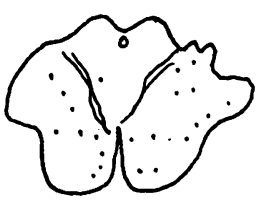

(f)

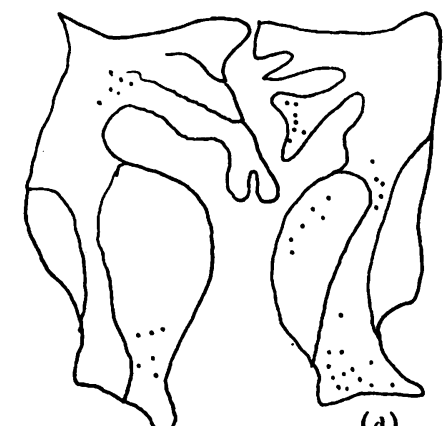

(d)

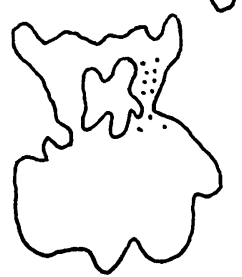

(g) (c)

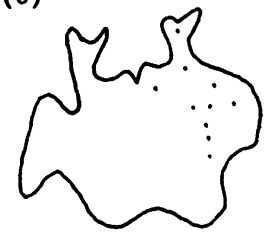

(h)

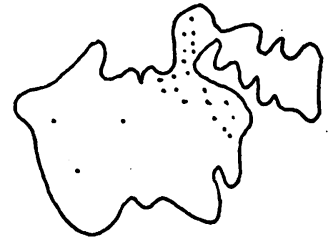

(i)

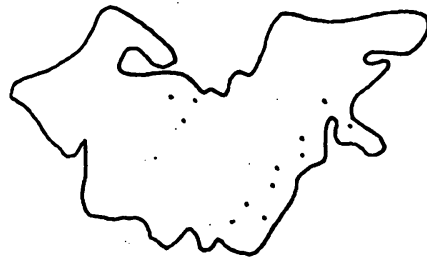

(j)

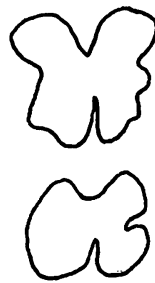

(k)

FIG. 5. Case 1. Distribution of microglial clusters. Each dot represents a single cluster. (a). Corpus callosum $1 \mathrm{~cm}$ posterior to the genu. (b). Corpus callosum between levels (a) and (c)/(d). (c), (d). Thalamus and corpus callosum at the level of the posterior limb of the internal capsule. (e). Splenium of the corpus callosum. (f), (g), (i). Sections at approximately $5 \mathrm{~mm}$ intervals through the upper pons. (h). Midbrain at the level of the superior colliculi. (j). Pons at the level of the middle cerebellar peduncle. (k), (l). Medulla at the rostral limit and the tip of the fourth ventricle respectively.

lateral to the lesions of the corpus callosum. The one exception to this was in the cingulate gyrus where lesions were on opposite sides to those of the corpus callosum. There, cerebral white matter lesions were maximal in the pre- and postcentral gyri and were on a plane immediately beneath the convolutions. Lesions of the grey matter were found in only six cases, three occurring in the thalamus, two in the cingulate cortex, and in one case in both these sites, although lesions were never plentiful in any of these.

The two cases further studied (cases 4 and 8 ) showed Marchi positive material in sites occupied in serial sections by microglial clusters, as confirmed by the Weil-Davenport and haema- toxylin and eosin staining methods. Such sites frequently showed disorganization of the fibre bundles, as shown by the Holmes staining technique, this often occurring in a position adjacent to a small blood vessel (See Fig. 9 and $c f$. findings by the Weil-Davenport method (Fig. 3)). Lesions showing retraction bulbs were few, but these were present in each case examined (Fig. 10) and were again in sites occupied by microglial clusters.

In certain cases microglial cells could be shown to have entered a phagocytic stage, whereupon they stained poorly with the Weil-Davenport stain but showed intracellular collections of neutral lipid droplets by the Herzheimer method. 
TABLE 2

DISTRIBUTION OF MICROGLIAL CLUSTERS

\begin{tabular}{|c|c|c|c|c|c|c|c|c|c|c|c|}
\hline & & & & & & Cas & & & & & \\
\hline & 1 & 2 & 3 & 4 & 6 & 7 & 8 & 9 & 10 & 11 & 12 \\
\hline Cerebrum & & & & & & & & & & & \\
\hline C.C. genu & $?$ & $\begin{array}{c}\mathbf{R}>\mathbf{L} \\
++\end{array}$ & $?$ & $\begin{array}{c}\mathbf{R}, \mathbf{L} \\
+++\end{array}$ & $?$ & $?$ & $\begin{array}{c}\mathbf{L}>\mathbf{R} \\
++\end{array}$ & $\begin{array}{l}\mathbf{L} \gg \mathbf{R} \\
+++\end{array}$ & $?$ & $\begin{array}{l}\mathbf{R}>\mathbf{L} \\
++\end{array}$ & $\begin{array}{c}\mathbf{R}>\mathbf{L} \\
++\end{array}$ \\
\hline C.C. ant. trunk & $\begin{array}{c}\mathbf{L}>\mathbf{R} \\
++\end{array}$ & $?$ & $?$ & $?$ & $\begin{array}{c}L \gg \mathbf{R} \\
++\end{array}$ & $?$ & $?$ & $\begin{array}{l}\mathbf{L} \gg \mathbf{R} \\
+++\end{array}$ & $?$ & $?$ & $?$ \\
\hline C.C. mid trunk & $\begin{array}{c}\mathbf{L}>\mathbf{R} \\
+\end{array}$ & R & $\mathbf{L} \gg \mathbf{R}$ & $\mathbf{R}, \mathbf{L}$ & $L>R$ & $L \gg R$ & $\mathbf{L}, \mathbf{R}$ & $L \gg R$ & $\mathbf{L}$ & 0 & $\mathbf{R}$ \\
\hline C.C. splenium & $\mathbf{L}>\mathbf{R}$ & $R>L$ & $L \gg R$ & ${ }_{\mathrm{L}}^{+}$ & $\begin{array}{l}+ \\
?\end{array}$ & $\begin{array}{l}+++ \\
\mathbf{L}>\mathbf{R}\end{array}$ & $\begin{array}{c}++ \\
\mathbf{L} \gg R\end{array}$ & $\begin{array}{l}+++ \\
\mathbf{L}>\mathbf{R}\end{array}$ & $\begin{array}{c}++ \\
\mathbf{L}>\mathbf{R}\end{array}$ & $?$ & $\begin{array}{c}++ \\
?\end{array}$ \\
\hline Int. capsule & $\begin{array}{l}\mathbf{R} \\
++\end{array}$ & $\begin{array}{c}+++ \\
\mathbf{L} \\
++\end{array}$ & $\begin{array}{l}+++ \\
\mathbf{R} \gg \mathbf{L} \\
+++\end{array}$ & $\begin{array}{c}+++ \\
\mathbf{R}>\mathbf{L} \\
++\end{array}$ & $\begin{array}{l}\mathbf{L} \\
+\end{array}$ & $\begin{array}{l}+ \\
\mathbf{R} \\
+\end{array}$ & $\begin{array}{l}+++ \\
\mathbf{R}>\mathbf{L} \\
+++\end{array}$ & $\begin{array}{c}++ \\
\mathbf{R}>\mathbf{L} \\
+++\end{array}$ & $\begin{array}{c}++ \\
\mathbf{R} \\
++\end{array}$ & 0 & $\begin{array}{l}\mathbf{L}>\mathbf{R} \\
++\end{array}$ \\
\hline Thalamus & $\begin{array}{c}\mathbf{L}, \mathbf{R} \\
+\end{array}$ & 0 & 0 & $\begin{array}{l}\mathbf{R} \\
+\end{array}$ & 0 & 0 & $\begin{array}{l}\text { L, R } \\
++\end{array}$ & 0 & $\begin{array}{c}\mathbf{R} \\
++\end{array}$ & $\mathbf{0}$ & $\begin{array}{l}\text { L, R } \\
+\end{array}$ \\
\hline Midbrain & & & & & & & & & & & \\
\hline Crura & $\begin{array}{c}\mathbf{L}, \mathbf{R} \\
+++\end{array}$ & $\begin{array}{c}\text { L } \\
++\end{array}$ & $\begin{array}{c}\mathbf{L}, \mathbf{R} \\
++\end{array}$ & $\begin{array}{l}\mathbf{R} \gg \mathbf{L} \\
+++\end{array}$ & 0 & $\begin{array}{l}\mathrm{L} \\
+\end{array}$ & $\begin{array}{c}\mathbf{R} \\
++\end{array}$ & 0 & $\begin{array}{l}\mathbf{R} \\
+\end{array}$ & $\begin{array}{l}\mathrm{L} \\
+\end{array}$ & $\begin{array}{c}\mathbf{L}>\mathbf{R} \\
++\end{array}$ \\
\hline M.l.f. & 0 & $\begin{array}{l}\mathbf{R} \\
+\end{array}$ & 0 & 0 & $\begin{array}{l}\text { L } \\
+\end{array}$ & 0 & 0 & $\begin{array}{l}\mathrm{R} \\
+\end{array}$ & $\begin{array}{l}\mathbf{R} \\
+\end{array}$ & 0 & $\begin{array}{l}\mathbf{R} \\
+\end{array}$ \\
\hline Sup. coll. & 0 & 0 & 0 & 0 & 0 & 0 & 0 & 0 & 0 & L & $\mathbf{L}, \mathbf{R}$ \\
\hline Inf. coll. & 0 & $\mathbf{0}$ & $\mathbf{0}$ & $\begin{array}{l}\mathbf{R} \\
+\end{array}$ & $\begin{array}{c}\text { L } \\
+\end{array}$ & $\begin{array}{c}\mathbf{L}, \mathbf{R} \\
+\end{array}$ & $\begin{array}{c}\mathbf{L}, \mathbf{R} \\
+\end{array}$ & 0 & $\begin{array}{l}\text { L, R } \\
++\end{array}$ & 0 & 0 \\
\hline Med. lemn. & $\begin{array}{l}\mathrm{L} \\
+\end{array}$ & $\begin{array}{c}\mathbf{L}, \mathbf{R} \\
+\end{array}$ & $\begin{array}{c}\text { L, R } \\
++\end{array}$ & $\begin{array}{c}\mathbf{L}, \mathbf{R} \\
++\end{array}$ & 0 & $\begin{array}{c}\mathbf{L} \\
++\end{array}$ & $\begin{array}{l}\mathbf{R} \\
+\end{array}$ & 0 & $\begin{array}{c}\text { L, R } \\
++\end{array}$ & 0 & $\begin{array}{l}\mathbf{L} \\
+\end{array}$ \\
\hline Decuss. sup. ped. & 0 & + & 0 & 0 & + & 0 & + & 0 & 0 & 0 & 0 \\
\hline Other sites & 0 & 0 & $\begin{array}{c}\text { RB } \\
+\end{array}$ & $\begin{array}{c}\text { RS } \\
+\end{array}$ & $\begin{array}{c}\text { RS } \\
+\end{array}$ & $\begin{array}{c}\text { RC } \\
+\end{array}$ & 0 & $\begin{array}{c}\text { RS } \\
+\end{array}$ & 0 & 0 & 0 \\
\hline Pons & & & & & & & & & & & \\
\hline Sup. ped. & $\begin{array}{c}\mathbf{R} \\
+++\end{array}$ & $\mathbf{0}$ & $\begin{array}{c}\mathbf{L}, \mathbf{R} \\
++\end{array}$ & $\begin{array}{c}\mathbf{R} \\
++\end{array}$ & 0 & $\begin{array}{l}\mathbf{R} \\
+\end{array}$ & $\begin{array}{c}\mathbf{R} \\
++\end{array}$ & $\begin{array}{c}\mathbf{R} \\
++\end{array}$ & $\begin{array}{c}\mathbf{R} \\
+++\end{array}$ & $\begin{array}{l}\mathbf{L} \\
+\end{array}$ & $\begin{array}{c}\mathbf{L} \\
++\end{array}$ \\
\hline Mid. ped. & $\begin{array}{c}\mathbf{R} \gg \mathbf{L} \\
++\end{array}$ & $\begin{array}{c}\text { L } \\
++\end{array}$ & $\begin{array}{c}\mathbf{R}>\mathbf{L} \\
++\end{array}$ & $\begin{array}{c}\mathbf{L}, \mathbf{R} \\
+\end{array}$ & $\begin{array}{l}\mathrm{R} \\
+\end{array}$ & $\begin{array}{c}\mathbf{R} \\
++\end{array}$ & $\begin{array}{l}\mathbf{R} \gg \mathbf{L} \\
+++\end{array}$ & $\begin{array}{c}\mathbf{R}>\mathbf{L} \\
++\end{array}$ & $\begin{array}{c}\mathbf{R} \\
++\end{array}$ & $\begin{array}{c}\mathbf{L}>\mathbf{R} \\
++\end{array}$ & $\begin{array}{c}\mathbf{L}>\mathbf{R} \\
++\end{array}$ \\
\hline M.1.f. & $\begin{array}{r}r \\
+\end{array}$ & $\begin{array}{l}\mathrm{L} \\
+\end{array}$ & 0 & $\begin{array}{l}\mathbf{R} \\
+\end{array}$ & $\begin{array}{l}\text { L } \\
+\end{array}$ & 0 & $\begin{array}{l}\mathbf{R} \\
+\end{array}$ & $\begin{array}{l}\mathbf{R} \\
+\end{array}$ & 0 & $\begin{array}{l}\mathbf{R} \\
+\end{array}$ & $\begin{array}{l}\mathrm{L} \\
+\end{array}$ \\
\hline Spino-thal. tract & 0 & 0 & 0 & 0 & $\begin{array}{l}\mathbf{R} \\
+\end{array}$ & 0 & 0 & $\begin{array}{l}\text { R } \\
+\end{array}$ & 0 & 0 & 0 \\
\hline Trapezoid body & 0 & 0 & 0 & 0 & 0 & 0 & + & 0 & 0 & 0 & 0 \\
\hline Medulla & & & & & & & & & & & \\
\hline Pyramid & 0 & 0 & 0 & 0 & $\begin{array}{l}\mathbf{R} \\
+\end{array}$ & $\begin{array}{l}\mathbf{R} \\
+\end{array}$ & $\begin{array}{l}\mathbf{R} \\
+\end{array}$ & 0 & $\begin{array}{l}\mathbf{R} \\
+\end{array}$ & 0 & 0 \\
\hline Inf. ped. & 0 & 0 & 0 & 0 & $\begin{array}{l}\mathbf{R} \\
+\end{array}$ & 0 & $\begin{array}{c}\mathbf{R} \\
+++\end{array}$ & 0 & 0 & 0 & $\begin{array}{c}\mathbf{L} \\
++\end{array}$ \\
\hline M.1.f. & 0 & 0 & 0 & 0 & 0 & $\begin{array}{l}\mathbf{L} \\
+\end{array}$ & $\begin{array}{l}\mathbf{R} \\
+\end{array}$ & 0 & 0 & $\begin{array}{l}\mathbf{R} \\
+\end{array}$ & $\begin{array}{l}\mathrm{L} \\
+\end{array}$ \\
\hline Lat. retic. & 0 & 0 & 0 & 0 & 0 & 0 & 0 & $\begin{array}{l}\mathbf{R} \\
+\end{array}$ & 0 & 0 & 0 \\
\hline
\end{tabular}

C.C. : corpus callosum. Int. capsule: internal capsule. M.l.f.: medial longitudinal fasciculus. Sup. coll.: superior colliculus. Inf. coll.: inferior colliculus. Med. lemn.: medial lemniscus. Lat. retic.: lateral reticular nucleus. Decuss. sup. ped.: decussation superior cerebellar peduncle. Mid. ped.: middle cerebellar peduncle. Spino-thal.: spino-thalamic. Inf. ped.: inferior cerebellar peduncle. L: left. R: right. B: brachium inferior cerebellar peduncle. S: spinothalamic tract. C: central tegmental tract. ?: site not examined. 0 : no lesions observed.

Plus signs indicate relative number of lesions in each site.

\section{DISCUSSION}

The results of the present study indicate that scattered areas of brain damage, visualized as microglial clusters identical with those described by Oppenheimer (1968), occur in a very high proportion of cases in which there has been head injury severe enough to cause loss of consciousness. Where haematoxylin and eosin sections were compared with Weil-Davenport sections the microglial clusters appeared identical with the microglial stars noted by Strich (1956a). That such lesions result from local trauma to nerve fibres is supported by the observation of axon disruption in sections stained by Holmes's method in sites occupied by microglial clusters.

Microglial clusters were invariably found in 


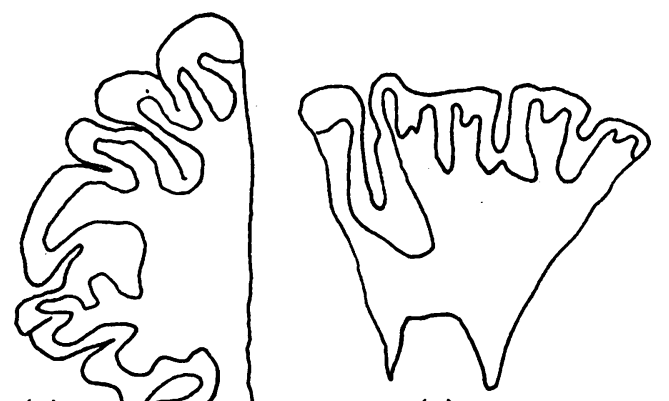

(b)

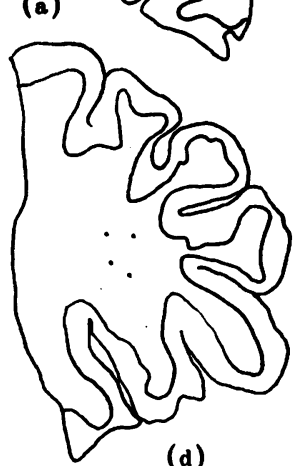

(d)

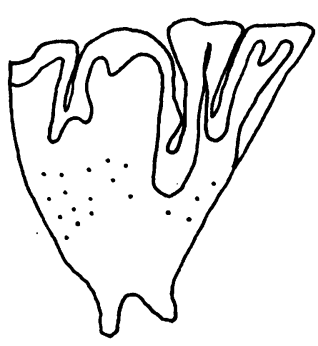

(e)

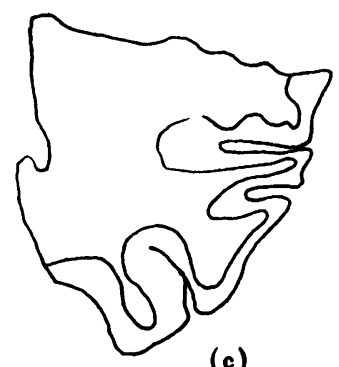

(c)

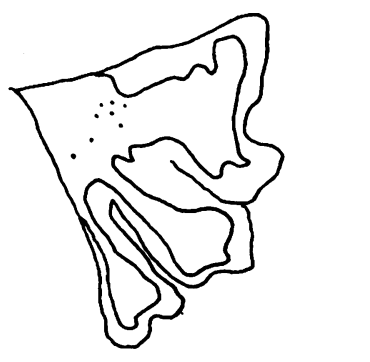

(f)
FIG. 6. Cases 4 and 5 (superimposed). Distribution of lesions in the cerebrum. (a), (b), and (c) are from the right hemisphere. (d), (e), and (f) from left. (a), (d). Cortex and underlying white matter of frontal lobes. (b), (e). Precentral gyrus. (c), (f). Occipital lobe. minute areas of softening visible to the naked eye and corresponding to the lesions noted by many workers. However, these lesions were frequently found where no macroscopic lesion was visible or associated with petechial haemorrhages and such lesions were almost invariably predictable in cases where external trauma had produced atrophy of the white matter with little other macroscopic injury.

Several mechanisms have been suggested in the papers by Oppenheimer and Strich to explain why the microglial clusters occur. One of these is that a shearing force is set up as the brain-stem rubs on the tentorium. Indeed, this seems the most likely explanation for the surface lesions which occur particularly in the midbrain and upper pons in the present cases. However, undoubtedly some microglial reaction is produced as a result of disruption of nerve fibres by petechial haemorrhages after the rupture of small blood vessels, and the frequent association between the two types of lesion has already been noted.

Nevertheless, both Oppenheimer and Strich considered that a reasonable proportion of these microglial clusters could arise from the direct snapping of axons by the setting up of shearing strains within the brain. This view that nerve fibres could be snapped by direct violence was first propounded by Gama in 1835 and later supported by Jakob (1913), but it was Holbourn $(1943,1945)$ who most fully developed the theory, mainly by the application of physical concepts to gelatin models of the brain. By these methods he showed that shearing forces, and not compression forces as suggested by DennyBrown and Russell (1941), were the most probable cause of the disruptive influence. Holbourn suggested that fibres might snap under such stretching forces, a view supported by the finding in sections stained for axons in the present study and in those of Rand and Courville (1934), Strich (1956), and Oppenheimer (1968). It is possible that the petechial haemorrhages occur when small blood vessels are similarly stretched by such forces. These mechanisms require the formation of shearing forces within the brain and again it is Holbourn who has explained how this may occur. He suggests that some external forces would set up a rotational movement within the skull of the cerebrum due to the inertia of the latter. Indeed, this has been 


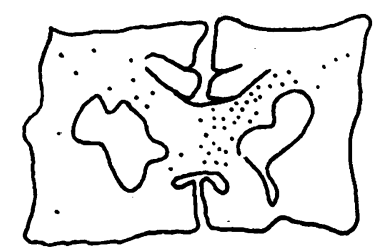

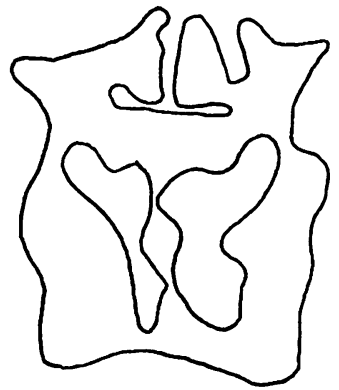

(b)

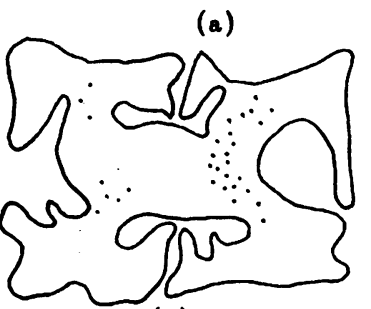

(e)

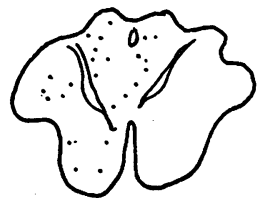

(i)

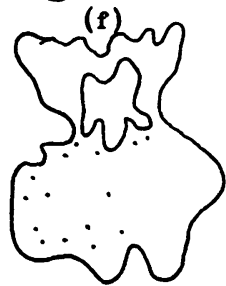

(i)
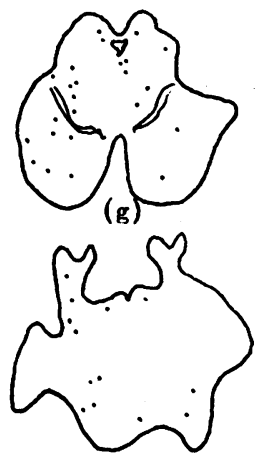

(j)

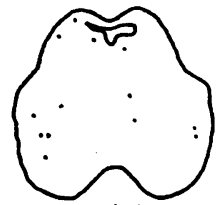

(h)

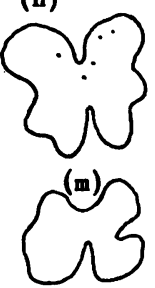

(in)

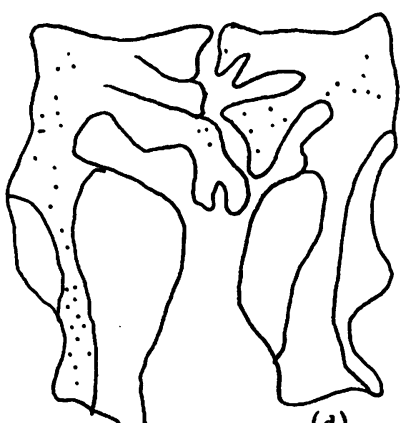

(d)

(c)
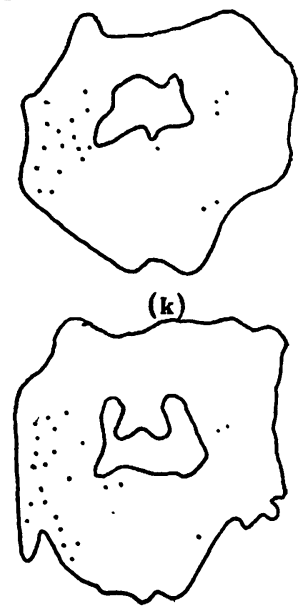

(1)

FIG. 7. Distribution of lesions in all cases with right sided external trauma. (a). Genu of corpus callosum. (b). Anterior trunk of corpus callosum. (c), (d). Corpus callosum and internal capsule. (e). Splenium of corpus callosum. (f). Upper midbrain. (g). Lower midbrain. (h). Isthmus of pons. (i), (j). Upper pons through the superior cerebellar peduncle. (b). Mid pons. (1). Lower pons. (m). Medulla immediately behind the pontomedullary junction. (n). Lower medulla.

shown to occur in monkeys (Pudenz and Sheldon, 1946). Furthermore, the subcortical distribution of stress which Holbourn predicts from such movement is closely paralleled by the site of microglial lesions in the present study.

This rotational movement has been shown to produce two roughly linear stresses at right angles in the two hemispheres (Strich, 1956) (see Fig. 11c). Thus the corpus callosum in one hemisphere and the internal capsule in the other hemisphere would be subjected to these forces. Undoubtedly this represents an over-simplification of the resolution of the forces within the brain but present results do tend to support the existence of such a resolution of forces.

Certainly the assumption that the corpus callosum and the internal capsule represent vertical and horizontal axes (as in Fig. 11c) is only partly true and applies only to the centre part of the internal capsule. However, the external force is unlikely to be applied in a single plane, and an obliquely applied force producing rotation in two planes would be likely to affect all parts of the internal capsule contralateral to the lesions in the corpus callosum (see Fig. 11b).

Probably the movements of the hemisphere 


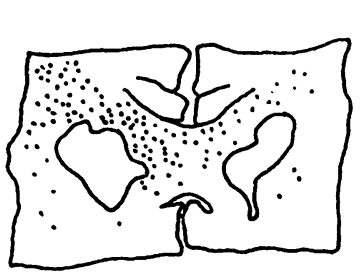

(a)

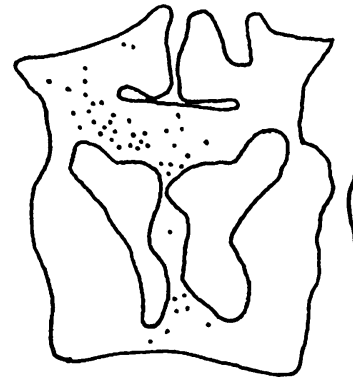

(b)

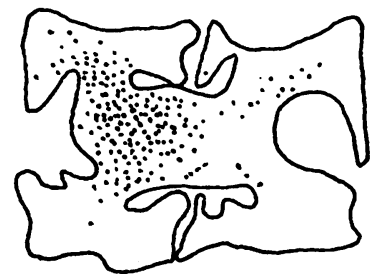

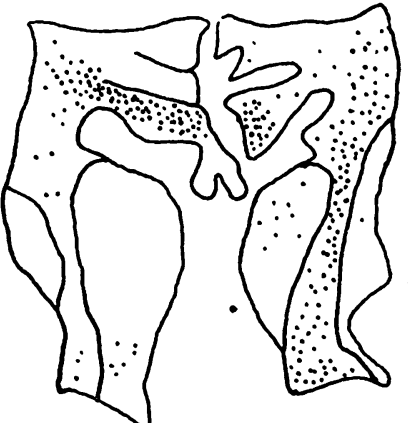

(d)

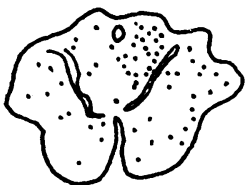

(f)

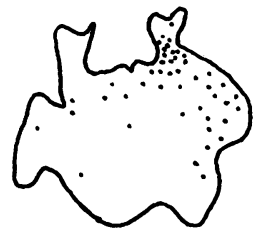

(j)

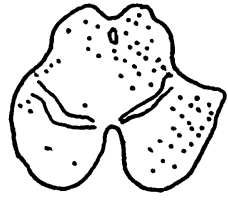

(g)

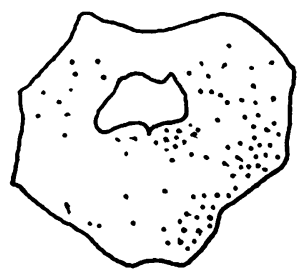

(k)

(e)

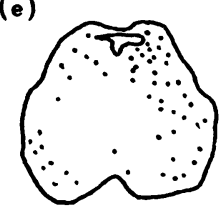

(h)

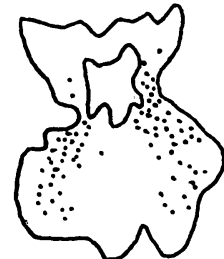

(i)

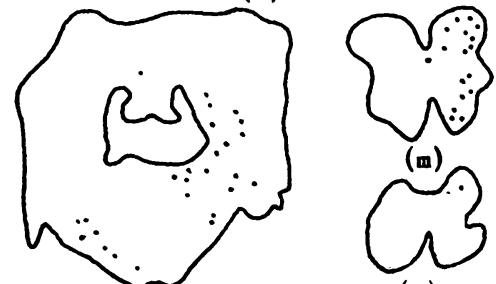

(n)

FIG. 8. Distribution of lesions in all cases with left sided external trauma. Levels are the same as in Fig. 6.

against the restraining force of the falx partly explain the distribution of lesions within the corpus callosum and almost certainly cause the lesions seen on occasions in the cingulate gyrus, often contralaterally to the maximal distribution of lesions in the corpus callosum (Fig. 11c).

The possible effects of rotational movements in the three planes are summarized in Fig. 11. It is probable that the results fit to the patterns in Fig. $11 \mathrm{c}$ and because the majority of external blows were lateralized to one side as indicated in these diagrams.

The distribution of brain-stem lesions ipsi- lateral to those in the internal capsule may be explained by the transmission of the stretching force to the brain-stem from the internal capsule, the hemisphere rotation tending to stretch one side of the hindbrain more than the other. As previously mentioned, the superficial lesions arise from the brain-stem movement against the tentorium, probably as a result of cerebral rotation. It is doubtful whether the closely investing leptomeningeal sheath which is said to protect the medulla from gross lesions (Lindenberg and Freytag, 1970) would be adequate to prevent the minute stretching required to disrupt 


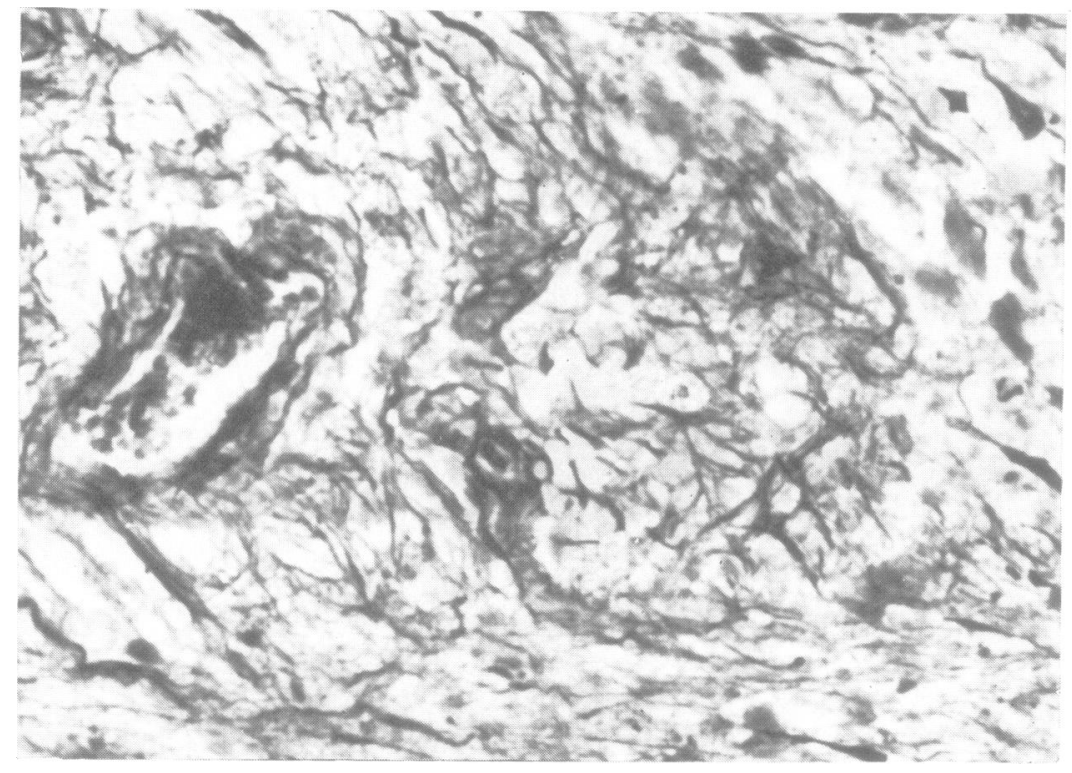

FIG. 9. Case 8. Photomicrograph of section from the superior cerebellar peduncle; 107 days' survival. Note the proximity of the blood vessel to the area of broken and tangled nerve fibres. General axis of fibres is diagonally from bottom right to top left. Holmes's preparation, $\times 75$.

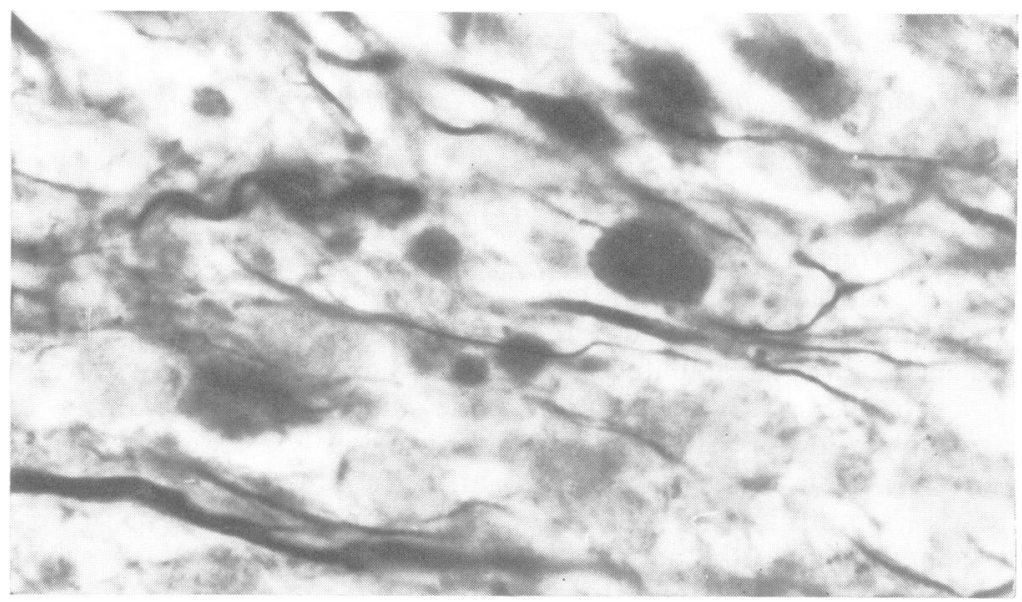

FIG. 10. Case 8. Higher magnification of section in Fig. 9. Note broken and tortuous fibres with retraction bulbs. $\times 375$. 


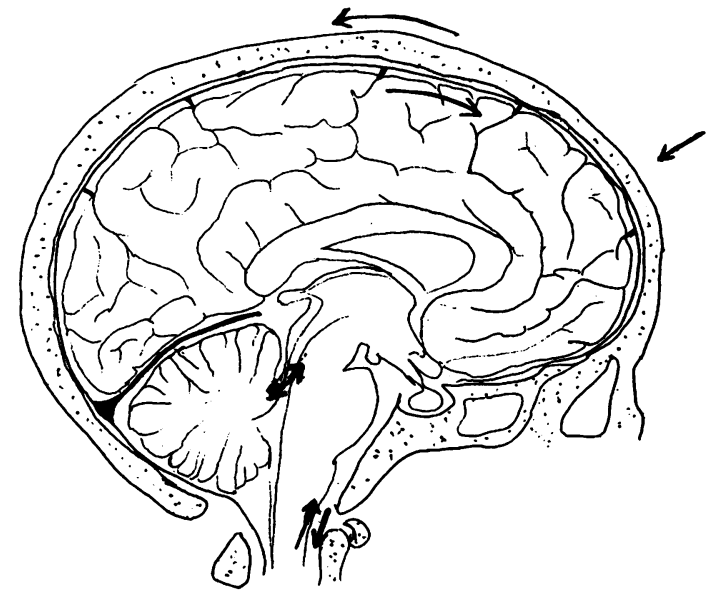

(a)

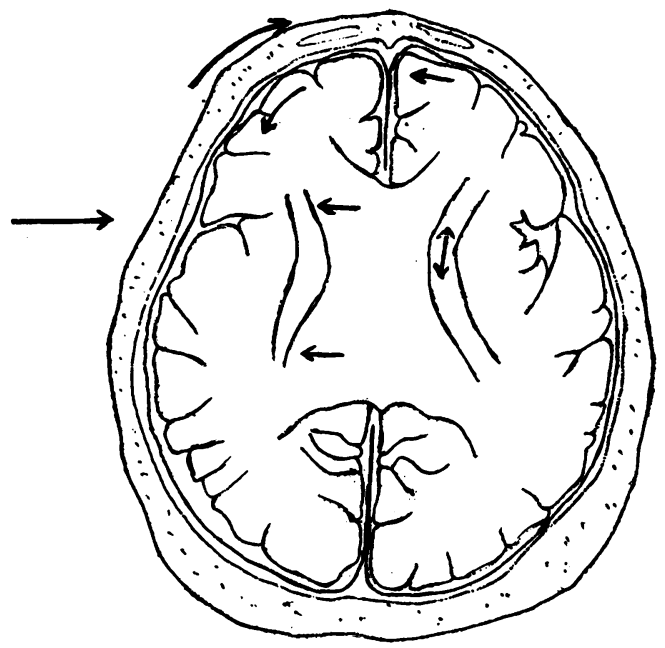

(b)

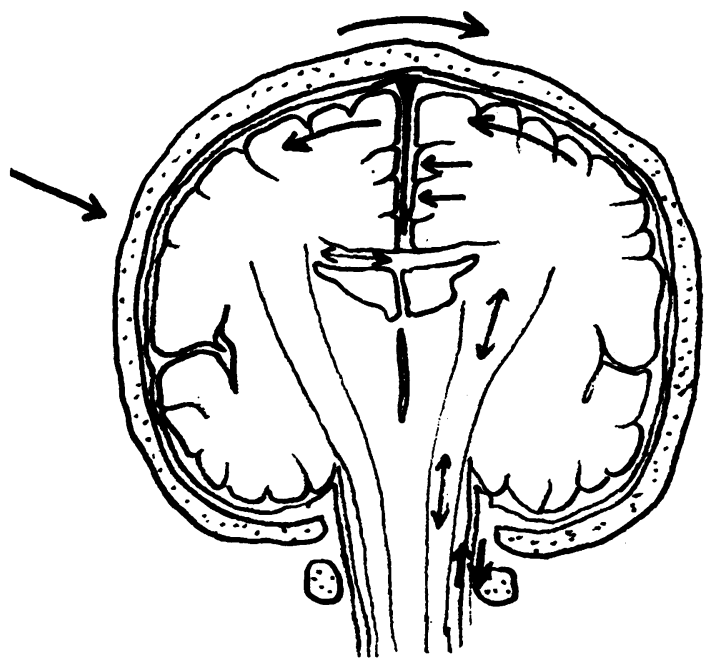

(c)

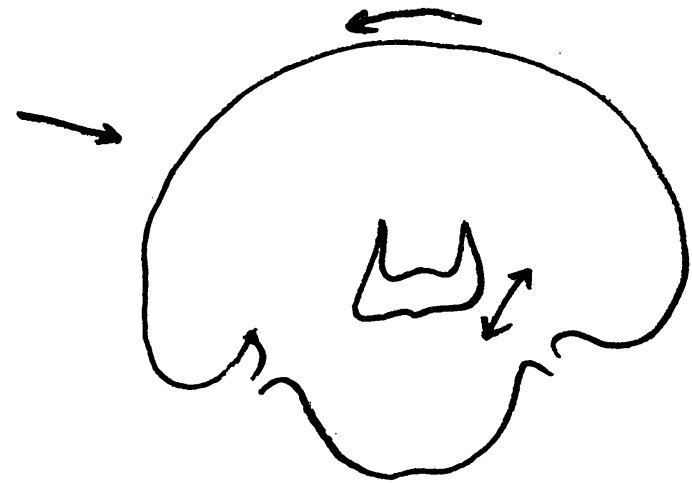

(d)

FIG. 11. a-d (s) to (c). Diagrammatic representation of the theoretical movements of the cerebrum in various planes, with a force applied to the skull. Arrows indicate the approximate line of action of the forces. Because of the inertia of the brain substance, relative movement of the cerebrum with respect to the skull is toward the external force, thereby producing deformity of the brain as a result of the partial fixation of the convexities of the hemispheres where surface veins drain into the sinuses. It is this deformity which gives rise to the shearing forces. Note the restraining influence of the falx and its influence on the theoretical distribution of forces and lesions.

individual axons, but certainly microglial clusters are rare in the medulla. Probably rotational forces acting on the cerebellum explain the lesions in the cerebellar peduncles, a lateral rotation producing only unilateral tension within the peduncles. If the mechanism producing the microglial clusters remains in doubt, it seems extremely likely that the frequent profound neurological changes associated with minimal gross trauma to the brain may be attributed to microscopic injury indicated by microglial clusters. 
I wish to thank Dr. Betty Brownell for the facilities she made available for the present study and for her encouragement and advice in planning the study. I am grateful to Mr. A. Churchill for his technical advice on preparing the sections.

\section{REFERENCES}

Bright, R. (1831). Reports of Medical Cases, Vol. 2, Part 2, p. 681. Longman: London.

Denny-Brown, D., and Russell, W. R. (1941). Experimental cerebral concussion. Brain, 64, 93-164.

Gama, J.-P. (1835). Traité des Plaies de Tête et de l'Encéphalite. 2nd edn. Crochard: Paris.

Holbourn, A. H. S. (1943). Mechanics of head injuries. Lancet, 2, 438-441.

Holbourn, A. H. S. (1945). Mechanics of brain injuries. British Medical Bulletin, 3, 147-149.

Jakob, A. (1913). Experimentalle Untersuchungen über die traumatischen Schädigungen des Zentralnervensystems (mit besonderer Berücksichtigung der Commotio cerebri und Kommotionsneurose). In Histologische und histopathologische Arbeiten über die Grosshirnrinde. Edited by F. Nissl, and A. Alzheimer, Vol. 5, pp. 182-358. Fischer: Jena.

Lindenberg, R., and Freytag, E. (1970). Brainstem lesions characteristic of traumatic hyperextension of the head. Archives of Pathology, 90, 509-515.
Luse, S. (1968). Microglia. In Pathology of the Nervous System. Vol. 1, pp. 531-538. Edited by J. Minckler. McGraw-Hill: New York.

Oppenheimer, D. R. (1968). Microscopic lesions in the brain following head injury. Journal of Neurology, Neurosurgery, and Psychiatry, 31, 299-306.

Pudenz, R. H., and Shelden, C. H. (1946). The lucite calvarium-a method for direct observation of the brain. II. Cranial trauma and brain movement. Journal of Neurosurgery, 3, 487-505.

Rand, C. W., and Courville, C. B. (1934). Histologic changes in the brain in cases of fatal injury to the head. 5 . Changes in the nerve fibers. Archives of Neurology and Psychiatry (Chic.), 31, 527-555.

Schmaus, H. (1899). Ueber den gegenwärtigen Stand der Lehre von der Commotio spinalis. Münchener Medicinische Wochenschrift, 46, 75-79.

Strich, S. J. (1956a). Diffuse degeneration of the cerebral white matter in severe dementia following head injury. Journal of Neurology, Neurosurgery, and Psychiatry, 19, 163-185.

Strich, S. J. (1956b). The pathological changes in the central nervous system of patients with profound traumatic dementia. D.M. Thesis, Oxford.

Strich, S. J. (1961). Shearing of nerve fibres as a cause of brain damage due to head injury. A pathological study of twenty cases. Lancet, 2, 443-448.

Weil, A., and Davenport, H. A. (1933). Staining of oligodendroglia and microglia in celloidin sections. Archives of Neurology and Psychiatry (Chic.), 30, 175-178. 